\title{
SPECTROMETRIC INVESTIGATION OF PIGMENTS AND SUBSTRATA IN WOOD PAINTINGS
}

\author{
CATALINA CHIOJDEANU, ANGELA VASILESCU, MIHAELA MANEA, FLORIN CONSTANTIN
}

Horia Hulubei National Institute of Physics and Nuclear Engineering Str. Reactorului no.30, P.O.BOX MG-6, Bucharest-Magurele, Romania ccatalina@nipne.ro,angela@nipne.ro,mmanea@nipne.ro,fconst@nipne.ro

JAMES SALIBA*

woodconservation@gmail.com

Published 25 February 2014

\begin{abstract}
A polychrome and gilded wooden artifact was found, in a heavily deteriorated state, in the stores of the Mdina Cathedral Museum, Malta. The object represents two zoomorphic angels holding a coat of arms. Stylistically, the artifact matches with parts of a late $16^{\text {th }}$ century Organ balcony, currently exhibited at the same Museum. The present study aims to establish whether or not the newly recovered artifact might have formed part of the balcony ensemble by means of material identification techniques. The combined use of XRF, FT-IR and FT-Raman spectroscopy ensure a detailed characterization of the material used. In the case of pigments, for both artifacts the blue pigment was smalt, while cinnabar was used for red and flesh tones. The metallic decorative parts of the panels are gilded, confirmed by the presence of Au peaks in the X-ray spectra. The supporting structure of both artifacts was manufactured from poplar wood.
\end{abstract}

Keywords: Polychrome wood; FTIR; XRF.

\section{Introduction}

Recent years have seen an increasing number of cases where a variety of analytic methods have been introduced for the characterization of pigments and manufacturing techniques of polychrome art works, such as paintings and sculptures. These studies use methods such as energy-dispersive X-ray fluorescence micro-Raman, and Fouriertransformed infrared spectroscopy to provide significant information to conservators, museum curators and art historians alike, leading to better insight for the preservation of cultural heritage. ${ }^{1-3}$

\footnotetext{
${ }^{*}$ Wood restorer.
}

This is an Open Access article published by World Scientific Publishing Company. It is distributed under the terms of the Creative Commons Attribution 3.0 (CC-BY) License. Further distribution of this work is permitted, provided the original work is properly cited. 


\section{Chiojdeanu et al.}

The first step in identifying the pigments used in the manufacturing of a polychrome artifact is typically XRF analysis. XRF is an elemental analysis technique, not a molecular one: each element has a characteristic XRF spectrum regardless of its molecular environment. The technique cannot be applied for elements of low atomic mass and is primarily utilized for the analysis of inorganic materials. The presence or absence of an element could suggest the use of a particular pigment. For example, the detection of mercury can be correlated with the use of vermillion, a red pigment produced artificially since the $8^{\text {th }}$ century; whereas the presence of lead might suggest the use of lead white (a basic lead carbonate, $\mathrm{Pb}(\mathrm{OH})_{2} \mathrm{CO}_{2}$ ) in the case of a white pigment, or the use of minium (lead tetraoxide, $\mathrm{Pb}_{3} \mathrm{O}_{4}$ ) in the case of a red one. The analysis may in some cases lead only to a reduction of possible pigments of the same color, since several pigments might contain the same element or elements. For example, for black, the presence of iron may suggest either ochre or another iron-containing pigment (e.g., Black Ochre: a mixture of a native impure oxide of carbon called black mineral, iron and alluvial clay, or Mars Black: $\mathrm{Fe}_{3} \mathrm{O}_{4}$ iron oxide pigment developed in the $20^{\text {th }}$ century). ${ }^{4}$

This methodology presents, however, a number of risks owing to the possibility of identifying several pigments containing the same element or elements, or even identifying a pigment only because in the XRF spectrum the elements appear to be present together, while they may be present in separate layers. Due to these issues, this method is typically used in combination with fingerprinting techniques such as Raman. The Raman technique is highly effective in identifying unknown materials, both organic and inorganic. Molecular specificity is inherent in vibrational spectroscopy, since molecular group frequencies and crystal lattice modes lead to unique vibrational spectra for specific materials, and even for materials that are compositionally identical but differ in either connectivity, e.g., realgar vs. pararealgar (a- and 7-As $\mathrm{S}_{4}$, respectively), or in their crystal structure, e.g., massicot vs. litharge (orthorhombic and tetragonal $\mathrm{PbO}$, respectively). Comparing the Raman spectrum of a sample to a library of spectra of possible materials usually yields an unambiguous match that leads to the identification of the otherwise unknown compound..$^{5-7}$

In this work, a complementary use of the above mentioned techniques was applied during the restoration process of two $16^{\text {th }}$ century polychrome wood artifacts to establish by material identification if they are part of the same ensemble.

\section{The Artifact}

A heavily deteriorated polychrome and gilded wooden artifact (Fig. 1, left) was recovered from the stores of the Mdina Cathedral Museum, Malta. During the documentation of the state of preservation, it was observed that the artifact matches stylistically to remnant parts of a late $16^{\text {th }}$ Organ Balcony (Fig. 1, right) exhibited in the same Museum. The study of the manufacturing technique, carving style and approach, leads us to hypothesize that the recuperated artifact might have belonged to the organ loft ensemble.

The work, in an unfortunate state of preservation, is a fine example of Late Mannerist gilded and polychromed wood carving. The center of production is not known, but a 
Neapolitan or Sicilian workshop seems likely. The possibility that it reached Malta with the new organ should not be overlooked. As a matter of fact, the entry concerning it is recorded along with the expenses for the importation and fixing of the new organ.

The gallery's three sides $(119 \mathrm{~cm}$ height), preserved to respective lengths of $69 \mathrm{~cm}$, $417 \mathrm{~cm}, 73 \mathrm{~cm}$, are remarkable for the decorative fantasy of their carved decoration in which the ornately rich balustraded rails carry grotesque masks and mermaids alternating with foliated columnettes. ${ }^{8}$

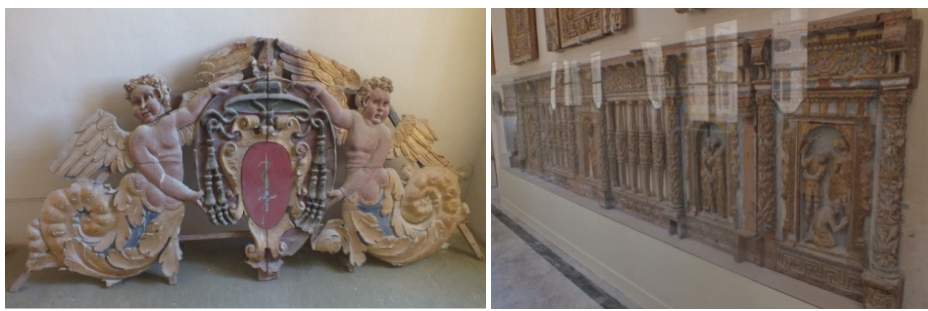

Fig.1. Left: the recovered polychrome wood artifact; Right: the Organ Balcony.

\section{Experiment}

Carefully collected samples of blue pigment, flesh tones and gold were analyzed for each artifact. The locations of the samples are identified as (i) the Angels artifacts (A) for samples collected from the two angels and (ii) The Organ Balcony (OB) for samples collected from the remnant parts of the Organ Balcony.

A preliminary characterization of the samples was obtained with an X-MET 3000TX+ portable XRF spectrometer (Oxford Instruments). The excitation X-ray beam for this spectrometer is generated by a $40 \mathrm{kV}$ tube with $\mathrm{Ag}$ anode. The detector resolution (a PIN silicon diode detector with Peltier cooling) is $270 \mathrm{eV}$ for the $\mathrm{Mn} \mathrm{K} \alpha$ line (5.89 $\mathrm{keV})$. The measurement spot size is about $30 \mathrm{~mm}^{2}$. The analyzer has a Hewlett-Packard (HP) iPAQ personal data assistant (PDA) for software management and data storage. ${ }^{9}$

FT-IR and FT-Raman spectra were acquired using a FT-IR/Raman Bruker Vertex 70 instrument equipped with two mobile probes, a MIR fiber with a $\mathrm{LN}_{2}$ cooled LN-MCT Mid detector and a RAMPROBE fiber with a $\mathrm{LN}_{2}$ cooled Ge detector, and a Nd:YAG laser of $1064 \mathrm{~nm}$ and 1-500 mW. FT-IR spectra were recorded between 650 and 4500 $\mathrm{cm}^{-1}$ with 1000 scans and FT-Raman between 50 and $3500 \mathrm{~cm}^{-1}$ with 500 scans. Resolution was in all cases $4 \mathrm{~cm}^{-1}$. The identification of pigments was made by comparison of their Raman spectra to our reference databases. ${ }^{10,11}$ A Micros Crocus II MCX100LCD biological microscope with integrated computer and real-time camera was used for the wood identification.

\section{Results and Discussions}

Pigments were first identified by means of XRF analysis according to the X-ray characteristic energies $(\mathrm{keV})$ in each spectrum, corresponding to specific chemical 


\section{Chiojdeanu et al.}

elements. Attribution of different pigments is based on previous consideration from literature. ${ }^{4}$ FT-Raman spectra provided more information on the pigments, while FTIR spectra gave more information on the organic content of painting.

\subsection{The blue pigment}

The results of the blue pigment analysis revealed a significant presence of Co and other elements such as $\mathrm{Ni}$ and As and traces of Bi. The presence of cobalt is a key element for smalt, while the metal impurities $(\mathrm{Ni}, \mathrm{As}, \mathrm{Bi})$ are indicators of mineral provenance used.

According to literature, only two possible sources were geologically rich enough in Co to support, for a long period of time, a trade route over Europe, North Africa and the East as far as China. These are the areas of Qamsar and Anarak in Persia and the Erzgebirge region in Saxony. The source localized in Erzgebirge mountain range, a center of cobalt pigment production (cobalt was obtained as secondary extraction products from silver ores, whose minerals are found admixed in the so-called 'fiveelement' $\mathrm{Ni}-\mathrm{Co}-\mathrm{As}-\mathrm{Ag}-\mathrm{Bi}$ veins) from as early as the $12^{\text {th }}$ century, matches with the pattern of the blue pigment collected from the Angels (A) as well as from the Organ Balcony (OB) artifacts. ${ }^{12}$

The amount of pigment used varies with the tone area - in the darker parts we found more Co (smalt) and less lead while opposite for lighter areas (less Co and more $\mathrm{Pb}$ ), making the correct identification of As and $\mathrm{Bi}$ difficult because of the interference of these elements with the $\mathrm{Pb} \mathrm{L}$ lines.

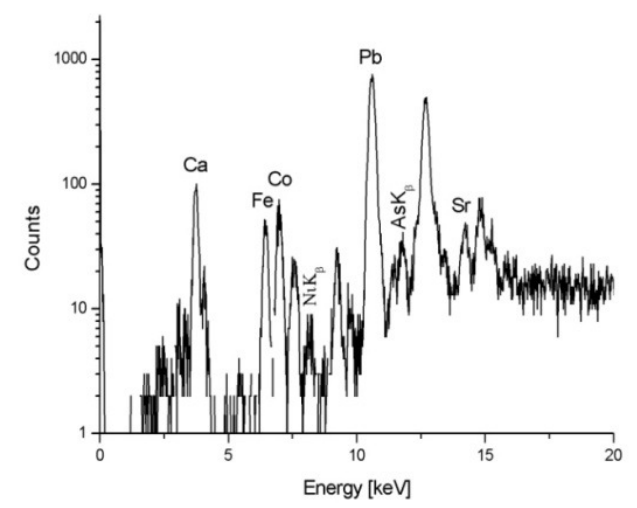

Fig. 2. XRF spectra obtained for the blue pigment collected from the Organ Balcony (OB).

Studies of the evolution of pigments used in $16^{\text {th }}-19^{\text {th }}$ century polychrome wood objects ${ }^{11}$ suggest the occurrence of $\mathrm{Ni}$, As and $\mathrm{Bi}$ impurities in Co-Blue pigment as an indicator of a $16^{\text {th }}-17^{\text {th }}$ century object. No spectral features except the ones characteristic of gypsum $\left(1010 \mathrm{~cm}^{-1}\right)$ and calcite $\left(1083 \mathrm{~cm}^{-1}\right)$ were identified from Raman spectra collected for the blue pigment. According to literature, smalt, the pigment identified by XRF analysis, cannot be detected using a $1064 \mathrm{~nm}$ laser as the excitation source. ${ }^{13}$ 


\subsection{The red/flesh tone pigment}

The chemical element identified in the flesh tone sample spectra is mercury $(\mathrm{Hg})$, the presence of which indicates that the red pigment used was cinnabar, a mercury sulfide $(\mathrm{HgS})-$ see Fig. 3. The $\mathrm{K}_{\alpha}(2.30 \mathrm{keV})$ and $\mathrm{K}_{\beta}(2.46 \mathrm{keV})$ peaks of $\mathrm{S}$ are covered by the $\mathrm{M}_{\alpha}(2.34 \mathrm{keV})$ and $\mathrm{M}_{\beta}(2.44 \mathrm{keV})$ peaks of $\mathrm{Pb}$ and therefore cannot be seen (Fig. 3).

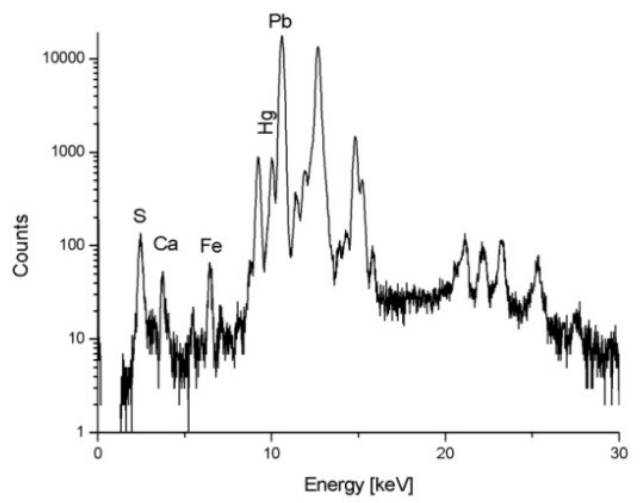

Fig. 3. XRF spectra obtained for the red pigment sample collected from the Organ Balcony (OB).

The Raman spectrum (Fig. 4) for the flesh tone samples revealed evidence of cinnabar, mercury (II) sulfide (HgS), with bands at 254, 286 and $345 \mathrm{~cm}^{-1}$, thus confirming the XRF results. The spectrum contains also a band at $1054 \mathrm{~cm}^{-1}$. This band is representative of calcium carbonate, which is probably the white pigment used to make the flesh tones from a red base color.

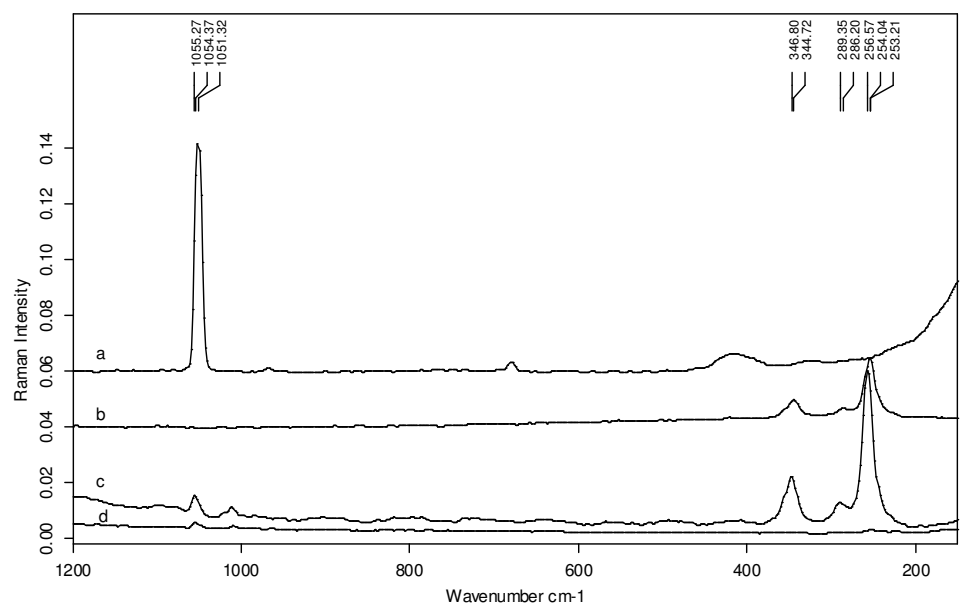

Fig. 4. FT-Raman spectra obtained for the a) red pigment, b) white lead standard, c) cinnabar standard flash color sample from the Angels (A), and d) skin flash color sample from the Organ Balcony (OB). 


\section{Chiojdeanu et al.}

\subsection{The metallic decorative parts}

High Au peaks confirm the presence of gold (Fig. 5) in the gold samples. High peaks of $\mathrm{Fe}$ in all the spectra reveal the presence of bole, red iron oxide, used in the preparation procedure in the gilding technique known as water gilding. Like many metals, gold does not give a first-order Raman spectrum, so it is virtually undetectable by this technique.

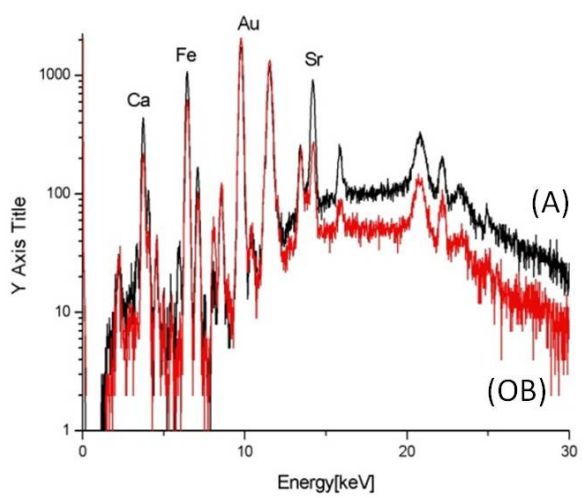

Fig. 5. X-Ray spectra obtained for gold samples from Angels (A) and Organ Balcony (OB).

\subsection{The preparation layer}

The occurrence of $\mathrm{Ca}, \mathrm{Fe}$, and $\mathrm{Sr}$ in all of the analyzed samples, suggests that these elements belong to the preparation layer. The presence of $\mathrm{Pb}$ in all the measured samples suggested that lead white $\left(2 \mathrm{PbCO}_{3} \mathrm{~Pb}(\mathrm{OH})_{2}\right)$ was the white pigment used. White lead is omnipresent: all the recorded Raman spectra contain the intense Raman band at $1,056 \mathrm{~cm}^{-1}$ (see Fig. 4), whereas the less intense bands of white lead at 260, 203 and $154 \mathrm{~cm}^{-1}$ are only observed in a few spectra. Apparently, this pigment was applied to modify the hue of the colored areas, making them appear brighter.

A compound based on $\mathrm{Ca}$ was used for the preparation layer (see X-ray spectra presented in Fig. 4). Two bands can be found at 1136 and $1010 \mathrm{~cm}^{-1}$ and three other very weak peaks at 674,499 and $417 \mathrm{~cm}^{-1}$ that are consistent with the presence of gypsumcalcium sulphate (Fig. 6).

\subsection{Wood identification}

The FT-IR spectra (Fig. 7) of the two wood samples show one strong hydrogen bound O$\mathrm{H}$ stretching absorption around $3400 \mathrm{~cm}^{-1}$ and a C-H stretching at $2917 \mathrm{~cm}^{-1}$. In the fingerprint region (between 1800 and $900 \mathrm{~cm}^{-1}$ ), some discrete absorbance bands due the various functionality of the wood constituents groups can be seen clearly: $\mathrm{C}=\mathrm{O}$ stretching (unconjugated) at $1733 \mathrm{~cm}^{-1}$, the aromatic skeletal vibration in lignin at $1508 \mathrm{~cm}^{-1}$, and other complex peaks describing carbohydrates and lignin various vibration modes localized in the fingerprint region below $1463 \mathrm{~cm}^{-1}$. 


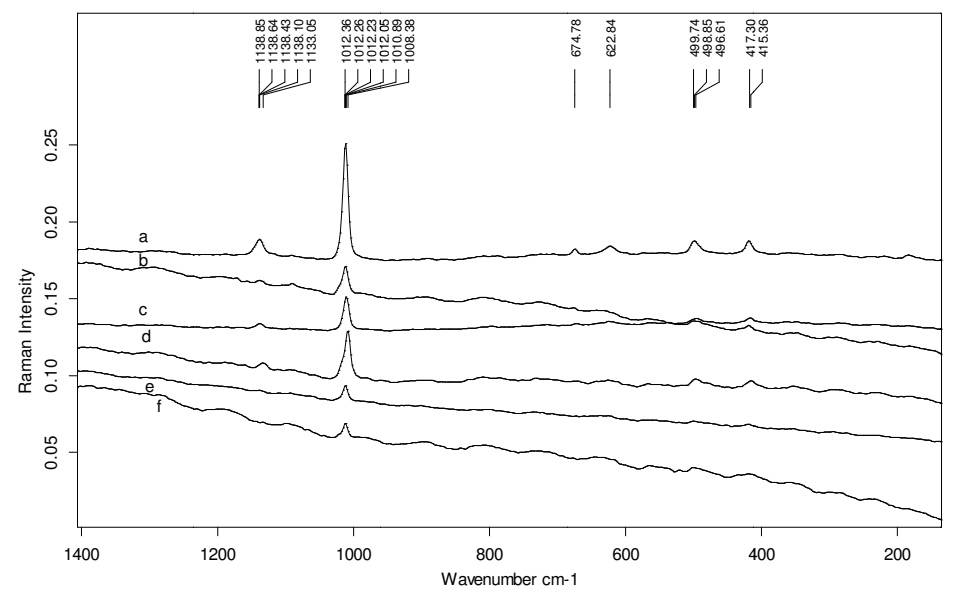

Fig. 6. FT-Raman spectra obtained for the preparation layer: a) \& b) the gold samples from Angels (A) and Organ Balcony (OB), respectively; c) Flash color sample from the Angels (A); d) Flash color sample from the Organ Balcony (OB); e) Blue sample from the Angels (A); f) Blue sample from the Organ Balcony (OB).

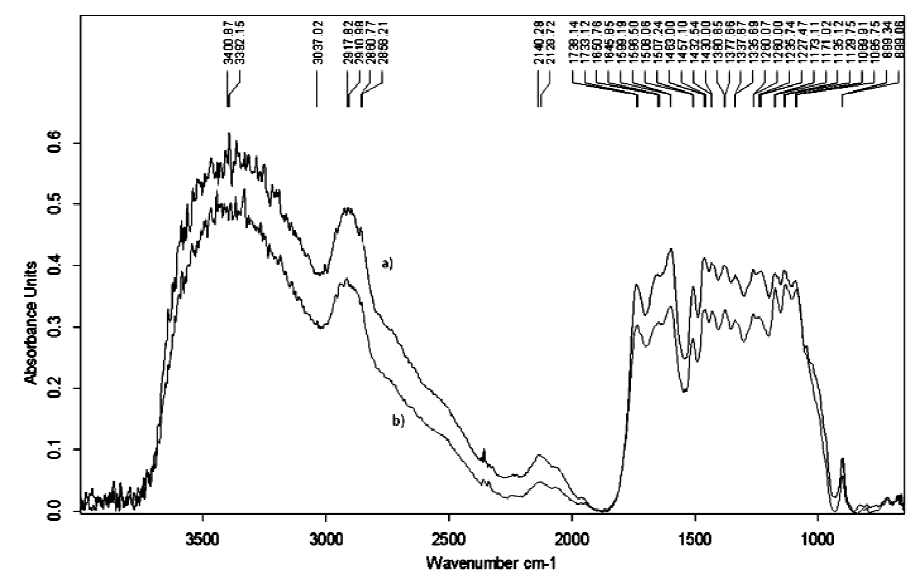

Fig. 7. FT-IR spectra of wood samples collected from the a) Angels (A) and b) Organ Balcony (OB).

No remarkable spectral differences were noticed in the case of the two samples; at this point we can conclude that the wood specie used is the same. It should be mentioned that the use of FTIR as a detection tool capable of differentiating between various wood types is conditioned by the existence of large reference databases containing FTIR spectra of the different species.

\subsection{Microscopic identification}

At microscopic inspection, the specie that has been analyzed was found to have diffuse porosity, with radially oriented vessels in multiples (see Fig. 8). The average vessel 


\section{Chiojdeanu et al.}

diameter was calculated as being 40-65-95 $\mu \mathrm{m}$. No helical thickenings have been observed, and tyloses were scarce but present. Rays were composed of a single cell type (homocellular) and exclusively uniseriate. Simple vessel perforations and large vessel-ray pits were observed. This structure is similar to the structure described in Ref. 14 for Populus (Poplar). Correlating these results with the visual analysis, we can finally validate that poplar was used for both artifacts.
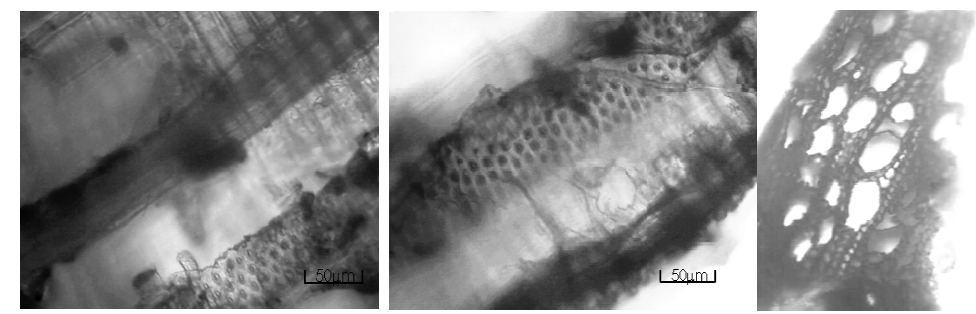

Fig. 8. Left: radial section of the wood sample showing ray tracheids and simple perforation plate. Center: radial section showing intervessel pitting. Right: Transverse section showing diffuse-porous.

\section{Conclusions}

This paper has presented the results of our analysis and material comparison of a late $16^{\text {th }}$ century polychrome wood organ balcony and a salvaged polychrome artifact. Such a detailed characterization of the materials and their successive stratification is a necessary task that must be accomplished prior to the commencement of any restoration intervention.

The analysis of the materials (pigments and preparation layer wood, etc.) was accomplished by combining the information obtained from X-ray fluorescence (XRF), Fourier-transform Raman spectroscopy (FT-Raman) and Fourier transform infrared (FTIR) spectroscopy. The materials used - blue pigment smalt, red pigment, cinnabar and gold for the decorative parts, and poplar for the wood - are identical, thus leading to the conclusion that the two artifacts are part of the same ensemble.

\section{Acknowledgments}

Funding from the Romanian National Scientific Research Agency grant PN2-RU-PD2011-3-0085 is gratefully acknowledged. Our special thanks go to all our collaborators: the Mdina Cathedral Museum, Mons. Aloysius Desira and Fr. Edgar Vella for facilitating the study.

\section{References}

1. L. P. Stodulski and V. J. Dorge, MRS Proceedings 185, 151 (1990)

2. B. H. Berrie, Annual Review of Anal. Chem. 5, 441 (2012)

3. L. Appolonia, et al., Anal. Bioanal. Chem. 395(7):2005-13, (2009).

4. R. Klockenkamper, A. von Bohlen and L. Moens, X-Ray Spectrom. 29, 1, (2000).

5. G. D. Smith and R. J. H. Clark, J. Arch. Sci. 31, 1137 (2004). 
6. E. Ciliberto, G. Spoto, Modern analytical methods in art and archaeology, in Chem. Anal. Series, Vol. 155 (Wiley, New York, 2000).

7. H. G. M. Edwards, J. M. Chalmers, Raman spectroscopy in archaeology and art history, in RSC Anal. Spectrum. Monographs (Royal Society of Chemistry, Cambridge, 2005).

8. Mario Buhagiar and Stanley Fiorini, Mdina - the Cathedral City of Malta Gutenberg Ltd, Tarxien, Malta, 1996.

9. S. Billets, XRF Technologies for Measuring Trace Elements in Soil and Sediment Oxford XMet 3000TX XRF Analyzer (Tetra Tech EM Inc., Ohio, 2006).

10. L. Burgio and R. J. H. Clark, Spectrochimica Acta Part A 57, 1491 (2001).

11. E. Smith and G. Dent, Modern Raman Spectroscopy, A Practical Approach (John Wiley \& Sons Ltd, UK, 2005), pp. 1-20.

12. A. Zucchiatti, A. Bouquillon, I. Katona and A. D'Alessandro, Archaeometry 48(1), 131 (2006).

13. K. Castro et al., Anal. Bioanal. Chem. 382, 248 (2005).

14. F. H. Schweingruber, Microscopic Wood Anatomy (Birmensdorf, 1982). 